\title{
FACTORS DEFINING THE EFFECTIVENESS OF INTEGRATED ACCOUNTING INFORMATION SYSTEM IN ERP ENVIRONMENT - EVIDENCE FROM VIETNAM'S ENTERPRISES
}

\author{
VU QUOC THONG \\ Ho Chi Minh City Open University, Vietnam - thongvu99@gmail.com \\ (Received: August 14, 2017; Revised: September 26, 2017; Accepted: October 31, 2017)
}

\begin{abstract}
The value of information system (IS) in business is crucial to the future of companies but is also prerequisite for business management. In our research, the IS value is estimated in the form of the effectiveness of integrated accounting information system (AIS) at organizational level. This paper explores factors that define the effectiveness of integrated AIS in organizations. The survey comprises of 316 businesses operating in Vietnam that have ERP-applied. Scale measurement construction for multi-dimensional concept and exploratory factor analysis (EFA) are used to validate and interpret the BSC-based research model. The result indicates that there are three groups of second order constructs including (1) business development support, (2) organizational process improvement and (3) market demand. They all define the effectiveness of integrated AIS in ERP environment. Each second order construct is defined by a set of first order constructs and related observed variables. The research provides business managers with a suggested model to evaluate the value of business information system, targeting in the integrated AIS in ERP environment.
\end{abstract}

Keywords: ERP-applied; Integrated AIS; The IS value.

\section{Introduction}

Accounting Information Systems (AIS) in IT 4.0 has become an important tool that helps enterprises improve their competitiveness and efficiency and adapt to changes (Huang et al., 2006; Lee et al., 2014). Compared with the 1990s, many enterprises have been skeptical about the actual value of AIS to enterprises' objectives in the 2000s (Carr, 2003). Many enterprises cannot sufficiently estimate the value of AIS due to the lack of defining measuring factors including qualitative and non-financial factors (Farbey et al., 1992). The result of this paper indicates the model to measure effectiveness of integrated AIS in ERP environment based on Balanced Scored Card (BSC) theory. Until 2010s, none of researches in Viet Nam applied BSC theory to the measurement model of factors defining the effectiveness of integrated AIS in ERP environment.

In the case we cannot measure the effects of AIS on the effectiveness of the enterprise; it is difficult to identify the value of AIS contribution to enterprises (Kohli \& Grover, 2008). Factors defining the effectiveness of integrated AIS in ERP environment is viewed as a manner to identify the value of AIS contribution to enterprises. There were various researches in the past focusing on the effect of Information System (IS) to enterprises. Joshi and Pant (2008) commented that these researches which were discrepant depend heavily on financial factors. For example, to evaluate the effects of IS to enterprise performance, financial factors including Cost-Volume-Profit analysis, ROI, NPV ratios... are still common choices (Cronk \& Fitzgerald, 1999). This leads to unilateral effect of the research results on the 
value of IS to enteprise. Milis and Mercken (2004) proposed the method of researching the effect of IS on enterprises to the combination of financial and non-financial factors when building the measurement model. In this paper, we try to build the model which includes qualitative and non-financial factors defining the effectiveness of integrated AIS in ERP-applied enterprise. This research attempts to explore factors defining the effectiveness of IS in specific ERP-applied enterprises AIS context from managers' viewpoint. This paper has the following objectives:

- To explore which factors define the effectiveness of integrated AIS in ERP environment?

- To test research model of factors defining the effectiveness of integrated AIS in ERP environment at enterprises operating in Vietnam?

The contents of this paper are written into four sections. The first section introduces a literature review. The second section mentions methodology, including the research model and measurement design. The third section presents the research findings and the last section says about conclusions, limitations and other future researches.

\section{Literature review}

\subsection{Around-the-world researches}

Melville et al. (2004) believed that the value of IS in business is the effect of IS on enterprises' performance; this effect can be realized at functional level and organizational level. To fully evaluate the effect of IS, Kohli and Grover (2008) proposed that the research should be placed in the organizational context rather than functional context.

There are various review articles contributing to the understanding of IS value in business. One of the salient work is conducted by DeLone and McLean (1992). DeLone and McLean (D\&M) reviewed 180 researches during the period of 1981 to 1988 and grouped them into 6 factors to measure the IS success. They consist of system quality, information quality, the use, user satisfaction, individual impact and organizational impact. Another classification of measuring factors for IS effectiveness came from Grover et al. (1996). He proposed 6 factors including infusion, market, economic, the use, conception and productivity. Until 1999 Seddon et al. commented on the IS success model of D\&M. This model did not consider different system stakeholder views in the IS evaluation. Different stakeholders such as managers, system designers or system users have different perception of the value of IS in business. To overcome the shortfall of D\&M IS success model, Seddon et al. developed a matrix into 2 dimensions to measure the effectiveness of IS. The matrix comprises stakeholder dimension and system dimension and it was developed from 186 researches published during the period of 1988 to 1996.

Next, Chan (2000) reviewed 38 researches from 1993 to 1998 to clarify the understanding of measuring the business IS value. He found that both quantitative and qualitative measures were used to evaluate IS at different levels including individual, unit, organization, industry and country. Apart from previous reviews, Shang and Seddon (2002) chose the context of enterprise system which integrates general ledger, purchasing, sales and inventory system to evaluate the IS value. They collected and analyzed 233 system evaluate scenarios from IS suppliers. They found 5 factors in the enterprise system evaluation releated to operational process, management, business strategy, IT infrastructure and organizational factors.

There is an obvious impact of IT to the alignment of the AIS and businesses after 2010. The convergence of financial and managerial accounting with the role of IT is a significant topic proposed in 2013 (Taipaleenmäki \& Ikäheimo, 2013). This 
issue attracts the researchers' great attention to the impact of IT on the integrated AIS in an organizational context. It is not clear that this impact leads to the boundary of financial and managerial accounting system once we evaluate the effective of AIS at organizational level. A qualitative research conducted by Lina and Edita (2014) pinpointed the development of AIS for the purpose of applying for business strategy under certain IT-supporting conditions such as ERP environment, Big data, Cloud computing and Business Intelligence. Based on the previous researches, we believe that factors defining the effectiveness of Integrated AIS and it is essential to place the AIS in an ERP environment and consider managers' viewpoints at organizational level.

\subsection{Related researches from vietnam}

During the period of 2002 to 2013, there are a few Vietnamese researches on AIS topic in the context of enterprises, corporations and public universities. However, these AIS researches just reach the line of formulating, organizing and proposing the AIS to business entities. The outstanding ones are organizing accounting systems in public sector under computerized conditions (Đào Văn Thành, 2002), proposing solutions to increase the quality of accounting jobs once applying accounting softwares (Trần Phước, 2007), organizing computerized accounting systems in import-export companies (Nguyễn Đăng Huy, 2011), improving AIS in public universities (Nguyễn Hữu Đồng, 2012), defining and controlling factors effecting accounting information quality in ERP environment (Nguyễn Bích Liên, 2013)... We realize that there are not any special researches for evaluating the effectiveness of integrated AIS in ERP environment from enterprise managers' viewpoints yet.

Due to the review from around- the-world and Viet Nam, we identify the need for a research to evaluate the IS in the specific ERP-AIS context. In this study, we present the BSC-based model and the results of new factors defining the effectiveness of integrated AIS in ERP environment at Vietnamese enterprises.

\section{Research methodology}

Many researchers have proposed guidelines to build a research model with the measurement scale (Churchill, 1979; Dunn et al., 1994; Mac Kenzie, 2005). Refer to previous research guidelines; we define stepby-step direction to implement this research (Table 1.). 


\section{Table 1}

Research direction summary

\begin{tabular}{|l|l|}
\hline $\begin{array}{l}\text { Step 1. Conceptualize theoretical } \\
\text { constructs }\end{array}$ & $\begin{array}{l}\text { We present related research concepts, theoretical model } \\
\text { Balance Score Card (BSC) and the research model. }\end{array}$ \\
\hline $\begin{array}{l}\text { Step 2. Identify preliminary observed } \\
\text { variables }\end{array}$ & $\begin{array}{l}\text { We review related articles, case-study... to collect } \\
\text { suitable variables for research constructs in the model. } \\
\text { Then, we work with ERP-AIS experts to select, classify } \\
\text { and modify observable variables. }\end{array}$ \\
\hline $\begin{array}{l}\text { Step 3. Conduct pretest and purify } \\
\text { observed variables }\end{array}$ & $\begin{array}{l}\text { The list of selected variables is arranged and modified } \\
\text { to form an initial survey. Next, we send it to ERP-AIS } \\
\text { experts to pretest the measurement scale. }\end{array}$ \\
\hline Step 4. Conduct a pilot test & $\begin{array}{l}\text { The survey after pretest is send to a small sample of 41 } \\
\text { Vietnamese enterprises which apply integrated AIS in } \\
\text { ERP environment. The purpose of pilot test is to check } \\
\text { initial dimension of research constructs. } \\
\text { The result of pilot test is the final questionnaire survey. }\end{array}$ \\
\hline $\begin{array}{l}\text { Step 5. Conduct main study } \\
\text { 6. Perform data analysis }\end{array}$ & $\begin{array}{l}\text { We do quantitative survey with a sample of 316 } \\
\text { Vietnamese enterprises which apply integrated AIS in } \\
\text { ERP environment. }\end{array}$ \\
\hline $\begin{array}{l}\text { Step use the survey results in Step 5 to analyze data, } \\
\text { including Explore Factor Analysis } \\
\text { EFA), adjusted research model and } \\
\text { Confirm Factor Analysis (CFA). }\end{array}$ & $\begin{array}{l}\text { perform EFA, reach an adjusted model with new factors } \\
\text { and perform CFA to confirm our research model. }\end{array}$ \\
\hline
\end{tabular}

The following sub sections mention the implementation of this research in detail.

\subsection{Conceptualize theoretical constructs}

AIS is an important part of enterprise system (Salehi, Rostami \& Mogadam, 2010). According to Bagranoff (2008), Romney and Steinbart (2012), AIS has a cross-road position between Accounting and Information System. This computer-based system is designed to help enterprise achieve 2 purposes related to decisional and control orientations. Grande et al. (2011) believed that the AIS is an integrated IS which assists enterprises in management and control aspects. The rapid development of IT has opened an opportunity for output and use of strategic accounting information for the whole organization. Enterprises need to organize an effective AIS in a suitable IT environment to meet accounting-business report requirements in fierce competition (El Louadi, 1998). Enterprises need to search for certain IT solutions which are able to fertilize the AIS for collecting data and distributing information across organization (Scapens \& Jazayeri, 2003; Grande et al., 2011). According to Gartner (2017), a world's leading IT research and advisory, such IT solutions refer to Enterprise resource planning (ERP) environment. ERP environment is defined as the ability to deliver an integrated suite of business applications, covering broad and deep operational end-to-end processes, which can be found in finance, $\mathrm{HR}$, distribution, manufacturing, service and the supply chain. ERP environment equipped in enterprises includes a group of computer applications in form of software modules which are integrated administrative and operational business processes (Daoud \& 
Triki, 2013).

Few researches on ERP solutions have been conducted at Vietnamese enterprises. These results classified ERP solutions into 2 types: foreign and domestic ERP solutions (Trần Thị Cẩm Thanh \& Đào Nhật Minh, 2015). The foreign ERP products have Oracle/ Oracle EBS, Microsoft Dynamics, Epicor/Scala... Meanwhile, the famous domestic ones include Fast Business, Lac Viet sureERP... Besides these on-the-shelf packages, there are self-developed ERP solutions by internal IS teams in big enterprises and corporations.

Integrated AIS is considered as an IS that has the ability to consolidate all business transactions of an enterprise with centralized database from which financial and nonfinancial data can be shared among other departments (Romney \& Steinbart, 2012). ERP environment is a suitable computerized system for applying integrated AIS at enterprises (Chapman \& Kihn, 2009). There are various accounting researches believe that ERP environment is a form of applied IT which is exogenous force impacting the AIS on the integrated and enterprise-wide orientation (Scapens \& Jazayeri, 2003; Rom \& Rohde, 2007). Bhimani and WillCocks (2014) published the research result with the assist of ERP environment and Big Data technology to explore accounting information system from integrated AIS.

To define the effectiveness in organizational control context, Georgopoulos and Tannenbaum (1957) believe that effectiveness is related to activities achieving an organization's objectives. According to Walton and Dawson (2001), the effectiveness of information system (IS) is the ability to assist business organizations to achieve the objectives. In our research, we focuss on the effectiveness of specific IS which is the integrated AIS in ERP environment. There are various difficulties in building the model to identify and validate factors defining the effectiveness of IS (Walton and Dawson, 2001).

Based on the previous researches, we believe that to fully evaluate the effectiveness of integrated AIS in ERP environment, we need to build the model including financial and non-financial factors. To put together the above theoretical concepts into a research model, we propose the theory of Balance Score Card, so-called BSC model. This theory is introduced by Kaplan and Norton (1992) with 4 theoretical constructs comprising financial, customer, internal process and growth and development (Figure 1.).

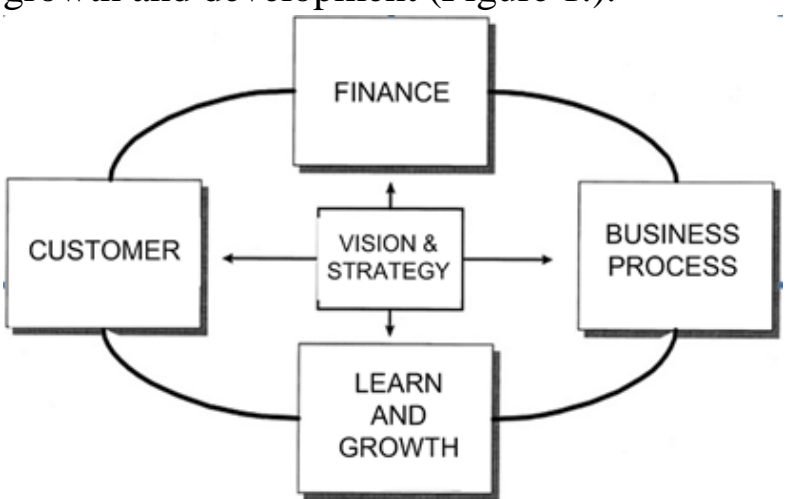

Figure 1. Balance Score Card theoretical model

BSC theory is a foundation of building the measurement scale for various managerial researches targeting on business performance. The IS value depends on the IS assistance for enterprises to achieve business objectives and implement business strategies (Lufman \& Brier, 1999). Many IS researchers have applied BSC model to investigate the impact of IS on business organizations. This theoretical model is suitable to construct an IS evaluation model with certain reasons:

- Multi-dimensional evaluation for implementing IS in enterprise across operational, tactic and strategic activities (Dasgupta et al., 1999; Schniederjans \& Hamaker, 2003).

- Identifying the measurement factors in BSC-based IS evaluation model which originates from objective and subjective 
(Thong \& Yap, 1996).

Besides, BSC model is considered as a suitable model to evaluate the effectiveness of integrated AIS since we compare the model with other IS theoretical models of IS evaluation such as IS success model from McLone and DeLean (1992) or User Information Satisfaction (UIS) moldel from Doll and Torkzadeh (1988). The UIS tool proposed by Doll and Torkzadeh when applied to evaluate the IS focus on the individual (user) level. Meanwhile, many researchers such as Grover et al. (1996) and Seddon (1997) confirm that IS success model from McLone and DeLean (1992) facing difficulty in IS evaluation by mixing individual and organizational views in the IS evaluating model. Many IS researchers have applied BSC model to investigate the impact of IS on business organizations (Kennerley and Neely, 2001; Sedera et al., 2001; Chand et al., 2005).

Refer to the concept of multi-dimensional construct from Nguyễn Đình Thọ (2013) and Edwards (2001), we propose the research model based on BSC theory. The research model states that the effectiveness of integrated AIS is a second-order construct defined by 4 first-order constructs including finance, customer, business process and learn and growth (Figure 2.). Although the secondorder construct is multi-dimensional one, the observed variables of each first-order construct need to be uni-dimensional.

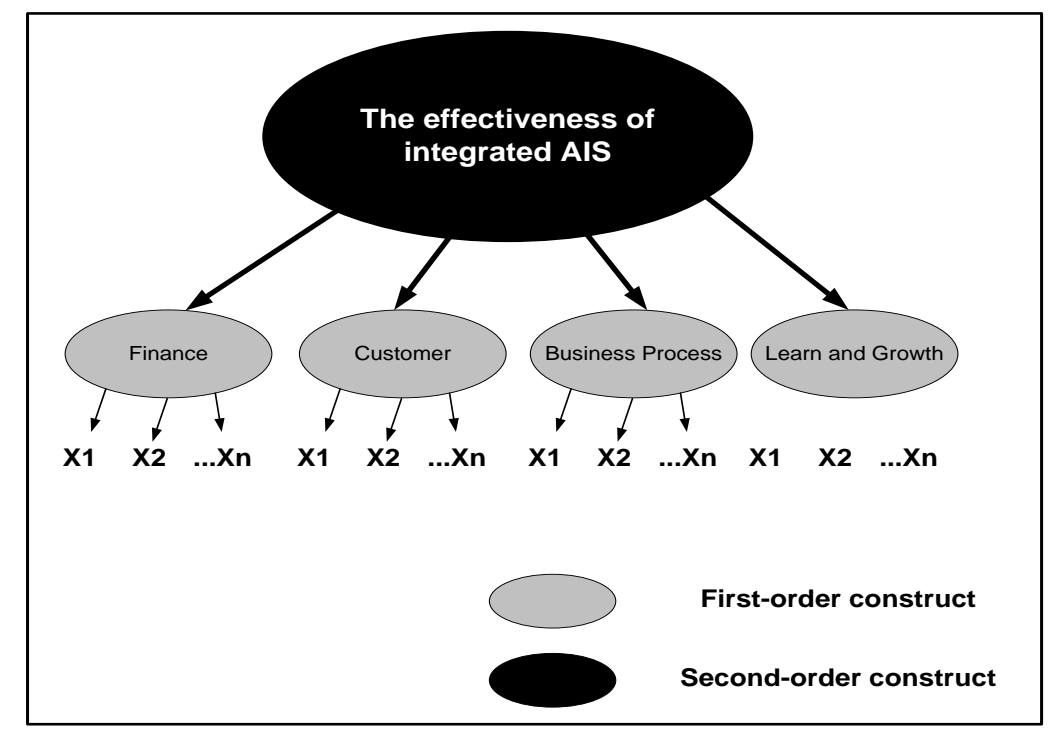

Figure 2. The initial research model

The following part mentions how we identify observed variables for measurement constructs.

\subsection{Identify preliminary observed variables}

We review related articles, case-study... to collect relevant observed variables for the first-order constructs in the research model. After collecting variables, we obtain the shortlist of 95 variables. According to Churchill (1979), the list of variables needs to be sorted by asking ERP-AIS experts to check the contents of variables and group them into a suitable measurement construct. There are 4 ERP-AIS experts invited to assist us to evaluate the variable list and put them into the suitable construct. A meeting would choose appropriate variables from at least 2 expert agreements. A final list consists of 47 variables. Furthermore, the experts suggest an additional list of variables measured for each construct. We select 17 similar-meaning variables suggested by at least 2 experts. 
Then, we work with ERP-AIS experts to modify the description of observed variables to improve the clarification.

\subsection{Conduct pretest and purify observed variables}

The identified variable list is used to develop an initial questionnaire survey. To pretest the questionnaire, there is another group of 6 ERP-AIS experts to read through every question in the survey. The experts comment on the contents of variables in each question. Next, we also conduct the item scale purification by assessing item-to-scale correlation. Pett et al. (2003) suggested deleting the variables with negative item-toscale correlation value. Then, we continue assessing item-to-item correlation. The signal of very high inner-item correlation (pair of variables with correlation values $>0.85$ ) is proposed that the variable is not suitable to the research construct (Miles \& Gilbert, 2005). The signal of low inner-item correlation (pair of variables with correlation values <0.30) indicates the low internal consistency reliability (Sundin et al., 2008). The above cases need to be removed from the variable list. In this research, we remove 3 variables from Finance construct, 1 variable from Customer construct and 1 variable from Learn and Growth construct. The Table 2. shows the result of variables list after conducting item purification.

\section{Table 2}

Variables list after conducting item purification

\begin{tabular}{|l|l|}
\hline \multicolumn{1}{|c|}{ Research construct } & \multicolumn{1}{c|}{ Number of observed variables } \\
\hline Finance (FINx) & 9 variables \\
\hline Customer (CUSx) & 7 variables \\
\hline Business Process (BUSx) & 20 variables \\
\hline Learn and Growth (LEAx) & 23 variables \\
\hline
\end{tabular}

\subsection{Conduct a pilot test}

After conducting item purification, a draft version of survey was sent to 41 enterprises' managers which have implemented integrated AIS in ERP environment. After collecting data in the pilot test, we perform Explore Factor Analysis (EFA) to reduce group of variables for each research construct (Nguyễn Đình Thọ, 2013). Using EFA with Principles Components Analysis in the purpose of evaluating measurement scale, at first we ensure the scale items to satisfy Bartlett's test of sphericity with $\mathrm{p}$ ratio $<5 \%$ and $\mathrm{KMO}$ checking with KMO indicator $>0.5$. Then, we follow the criteria to delete scale items which are loaded less than 0.5 or loaded greater than 0.5 (Hair et al., 2005).
The result of EFA shows:

- Finance construct including 2 groups of factors, named FaFIN1 and FaFIN2;

- Customer construct including 2 groups of factors, named FaCUS1 and FaCUS2;

- Business Process construct including 4 groups of factors, named FaBUS1, FaBUS2, FaBUS3 and FaBUS4;

- Learn and Growth construct including 4 groups of factors, named FaLEA1, FaLEA2, FaLEA3 and FaLEA4.

In summary, there are 47 variables presented in the form of questions in the final survey (Table 3.). The final survey is proved on the content validity and measurement reliability. 


\section{Table 3}

Variables list after conducting a pilot test

\begin{tabular}{|l|l|}
\hline \multicolumn{1}{|c|}{ Research construct } & \multicolumn{1}{c|}{ Number of observed variables } \\
\hline Finance (FINx) & 9 variables \\
\hline Customer (CUSx) & 6 variables \\
\hline Business Process (BUSx) & 14 variables \\
\hline Learn and Growth (LEAx) & 18 variables \\
\hline
\end{tabular}

Once completing the final questionnaire survey, we conduct the quantitative research with the massive survey distribution to 316 Vietnamese enterprises which have implemented integrated AIS in ERP environment. The enterprise managers are the target of survey respondents which comprise $\mathrm{CEO}, \mathrm{CFO}, \mathrm{CIO}$, chief accountants, departments' managers... The data collection process lasts around 2 years from 2015 to 2016. Finally, we collect a sample of 147 valid respondents ( $47 \%$ of sending surveys).

\section{Findings}

\subsection{Exploratory factor analysis (efa)}

This section provides the results of the research. We use the collected data to perform Exploratory Factor Analysis (EFA) for the purpose of exploring new factors defining the effectiveness of integrated AIS in ERP environment. In EFA, we extract factors with Principles Components Analysis and rotate them with Varimax method. At first, we test each construct by ensuring Bartlett's test of sphericity with $\mathrm{p}$ ratio $<5 \%$ and $\mathrm{KMO}$ checking with KMO indicator $>0.5$.

With the collected data, the result of EFA shows (Table 4.):

- Finance construct including 2 groups of factors, named FaFIN1 and FaFIN2;

- Customer construct including 2 groups of factors, named FaCUS1 and FaCUS2;

- Business Process construct including 4 groups of factors, named FaBUS1, FaBUS2, FaBUS3 and FaBUS4;

- Learn and Growth construct including 3 groups of factors, named FaLEA1, FaLEA2 and FaLEA3.

\section{Table 4}

The result of Exploratory Factor Analysis

\begin{tabular}{|l|c|c|c|c|c|c|c|}
\hline Construct & KMO & $\begin{array}{c}\text { Bartlett } \\
\text { test }\end{array}$ & Factors & $\begin{array}{c}\text { Variables } \\
\text { No. }\end{array}$ & $\begin{array}{c}\text { Cronbach's } \\
\text { alpha }\end{array}$ & $\begin{array}{c}\text { Cumulative } \\
\text { \% of } \\
\text { Extraction }\end{array}$ & Eigenvalue \\
\hline Finance & 0.802 & 0.0 & FaFIN1 & 6 & 0.862 & 46.283 & 4.174 \\
& & & FaFIN2 & 3 & 0.745 & 61.403 & 1.822 \\
\hline Customer & 0.744 & 0.0 & FaCUS1 & 4 & 0.862 & 54.634 & 3.512 \\
& & & FaCUS2 & 2 & 0.706 & 72.523 & 1.108 \\
\hline Business & 0.698 & 0.0 & FaBUS1 & 3 & 0.793 & 35.907 & 4.239 \\
Process & & & FaBUS2 & 4 & 0.767 & 50.732 & 2.018 \\
& & & FaBUS3 & 3 & 0.795 & 67.832 & 1.625 \\
\hline Learn and & 0.796 & 0.0 & FaLEA1 & 8 & 0.894 & 45.062 & 6.259 \\
Growth & & & FaLEA2 & 3 & 0.788 & 51.237 & 1.864 \\
& & & FaLEA3 & 3 & 0.792 & 60.496 & 1.130 \\
\hline
\end{tabular}




\subsection{Adjusted research model}

The underlying theory BSC shows that there is the relationship to 4 main constructs: finance, customer, business process and learn and growth. To identify the correlation among these constructs, the matrix with p-value is used. Table 5. illustrates significant correlation among factors of 4 main constructs. Therefore, we continue with further analysis to explore new high-order constructs (Evan, 1999; Bassellier et al., 2003; Blackburn et al., 2005).

\section{Table 5}

The correlation matrix

\begin{tabular}{|c|c|c|c|c|c|c|c|c|c|c|c|c|c|c|}
\hline Factors & Mean & $\begin{array}{c}\text { Standard } \\
\text { Deviation }\end{array}$ & $\begin{array}{c}\text { item-to-total } \\
\text { correlation }\end{array}$ & FaFIN1 & FaFIN2 & FaCUS1 & FaCUS2 & FaBUS1 & FaBUS2 & FaBUS3 & FaBUS4 & FaLEA1 & FaLEA2 & FaLEA3 \\
\hline FaFIN1 & 3.914 & 0.640 & 0.462 & 1.000 & & & & & & & & & \\
\hline FaFIN2 & 3.906 & 0.683 & 0.451 & $0.407^{* *}$ & 1.000 & & & & & & & & \\
\hline FaCUS1 & 4.134 & 0.587 & 0.562 & $0.534^{* *}$ & $0.176^{*}$ & 1.000 & & & & & & & \\
\hline FaCUS2 & 3.336 & 0.991 & 0.424 & $0.202^{*}$ & $0.253^{* *}$ & $0.311^{* *}$ & 1.000 & & & & & & \\
\hline FaBUS1 & 3.938 & 0.944 & 0.421 & 0.079 & $0.166^{*}$ & $0.246^{* *}$ & $0.359^{* *}$ & 1.000 & & & & & & \\
\hline FaBUS2 & 3.994 & 0.619 & 0.545 & $0.280^{* *}$ & $0.409^{* *}$ & $0.479^{* *}$ & $0.172^{*}$ & $0.329^{* *}$ & 1.000 & & & & \\
\hline FaBUS3 & 3.212 & 0.926 & 0.530 & $0.348^{* *}$ & $0.224^{* *}$ & $0.286^{* *}$ & $0.413^{* *}$ & $0.409^{* *}$ & $0.271^{* *}$ & 1.000 & & & \\
\hline FaBUS4 & 3.887 & 0.778 & 0.378 & 0.060 & $0.330^{*}$ & 0.129 & $0.170^{*}$ & $0.250^{* *}$ & $0.316^{* *}$ & $0.238^{* *}$ & 1.000 & & \\
\hline FaLEA1 & 3.577 & 0.599 & 0.671 & $0.288^{* *}$ & $0.339^{*}$ & $0.437^{* *}$ & $0.357^{* *}$ & $0.368^{* *}$ & $0.362^{* *}$ & $0.450^{* *}$ & $0.405^{* *}$ & 1.000 & \\
\hline FaLEA2 & 3.990 & 0.643 & 0.628 & $0.389^{* *}$ & $0.386^{* *}$ & $0.390^{* *}$ & 0.118 & 0.147 & $0.487^{* *}$ & $0.178^{*}$ & $0.395^{* *}$ & $0.508^{* *}$ & 1.000 & \\
\hline FaLEA3 & 3.867 & 0.616 & 0.429 & $0.406^{* *}$ & 0.113 & $0.542^{* *}$ & 0.146 & 0.124 & $0.258^{* *}$ & $0.298^{* *}$ & 0.045 & $0.474^{* *}$ & $0.425^{* *}$ & 1.000 \\
\hline
\end{tabular}

$*$ p-value $<0.05, * *$ p-value $<0.01$ (two-tail test of significance)

The result of second-order construct is showed below (Table 6.):

\section{Table 6}

3 new second-order constructs

\begin{tabular}{|c|c|c|c|}
\hline Fisrt order construct & $\begin{array}{c}\text { Second order } \\
\text { construct } \\
\text { FaNEW1 }\end{array}$ & $\begin{array}{c}\text { Second order } \\
\text { construct } \\
\text { FaNEW2 }\end{array}$ & $\begin{array}{c}\text { Second order } \\
\text { construct }\end{array}$ \\
\hline FaLEA3 & 0.836 & FaNEW3 \\
FaCUS1 & 0.779 & 0.835 & \\
FaFIN1 & 0.741 & 0.711 & \\
FaBUS4 & & 0.664 & \\
FaFIN2 & & 0.602 & \\
FaLEA2 & & & 0.763 \\
FaBUS2 & & & 0.757 \\
FaCUS2 & & & 0.704 \\
FaBUS1 & 36.937 & 49.596 & 0.701 \\
FaBUS3 & 3.595 & 1.361 & 60.942 \\
\hline Cronbach's alpha & & & 1.287 \\
\hline Eumulative \% of Extraction & & & \\
\hline
\end{tabular}


We continue to identify the correlation among 3 new second-order constructs by using the matrix with p-value (Table 7.). There is a significant correlation among 3 new second-order constructs.

\begin{tabular}{|c|c|c|c|c|c|c|}
\hline $\begin{array}{c}\text { Second-order } \\
\text { Factors }\end{array}$ & Mean & $\begin{array}{c}\text { Standard } \\
\text { Deviation }\end{array}$ & $\begin{array}{c}\text { item-to-total } \\
\text { correlation }\end{array}$ & FaNEW1 & FaNEW2 & FaNEW3 \\
\hline FaNEW1 & 3.962 & 0.501 & 0.464 & 1.000 & & \\
\hline FaNEW2 & 3.947 & 0.498 & 0.485 & $0.423 * *$ & 1.000 & \\
\hline FaNEW3 & 3.551 & 0.742 & 0.4319 & $0.358 * *$ & $0.367 * *$ & 1.000 \\
\hline
\end{tabular}

$*$ p-value $<0.05, * *$ p-value $<0.01$ (two-tail test of significance)

Then, we continue with further analysis to explore new high-order constructs. The result of thirdorder construct is showed below (Table 7.):

\section{Table 7}

Third-order construct

\begin{tabular}{|c|c|}
\hline Second-order factors & $\begin{array}{c}\text { Main construct } \\
\text { FaTOTAL }\end{array}$ \\
\hline FaNEW1 & 0.785 \\
FaNEW2 & 0.771 \\
FaNEW3 & 0.764 \\
\hline Cronbach's alpha & 0.703 \\
Cumulative \% of Extraction & 59.216 \\
Eigenvalue & 1.808 \\
\hline
\end{tabular}

By performing Exploratory Factor Analysis, we find new factors defining the effectiveness of integrated AIS in ERP environment. Compared to initial research model (Figure 2.), the adjusted model includes 10 first-order constructs grouped into 3 second-order constructs (FaNEW1, FaNEW2 and FaNEW3) which define the main construct effectiveness of integrated AIS (FaTOTAL). Refer to Evans (1999), we consider the content and meaning of variables loaded to each first-order construct to name the first-order constructs. The explored firstorder constructs include:

- FaFIN1: Financial profit

- FaFIN2: Cost saving

- FaCUS1: Customer management

- FaCUS2: Customer care

- FaBUS1: Production efficiency
- FaBUS2: Internal management efficiency

- FaBUS3: Product Improvement

- FaBUS4: Working process improvement

- FaLEA2: Working corporation

- FaLEA3: Business competitiveness

The naming of three second-order constructs FaNEW1, FaNEW2 and FaNEW3 are based on the content and meaning of loaded first-order constructs and the IT implications in business performance:

- FaNEW1: Business development support

- FaNEW2: Organizational process improvement

- FaNEW3: Market demand meet

The main construct FaTOTAL is the grouping of 3 second-order constructs. It is a third-order construct named the effectiveness of integrated AIS. (Figure 3.), illustrates the research adjusted model. 


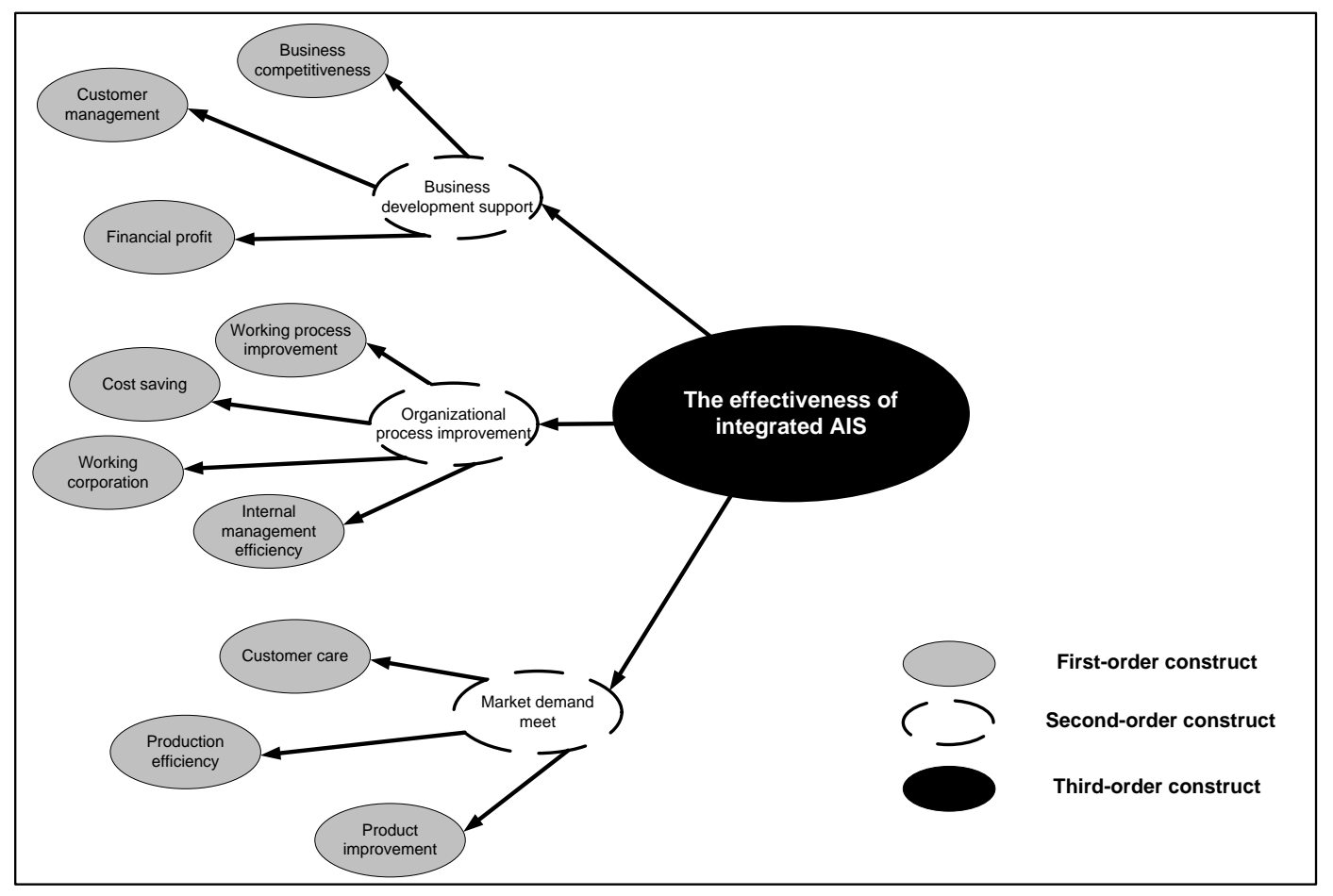

Figure 3. The adjusted research model

\section{3. the meaning of the new factors}

Information Technology has a significant impact on organizational change (Wikina, 2008). Refer to Wikina research results (2008), we discuss the name of each secondorder construct which contribute to the meaning of the effectiveness of integrated AIS (main construct).

- FaNEW1: Business development support, once integrated AIS in ERP environment enables the combination of data flow across departments from front-end unit like sales department to back-end unit including accounting and finance unit, such AIS clearly helps enterprises achieve the effectiveness by improving business competitiveness (FaLEA3) and obtain financial profit (FaFIN1). The financial profit can be assessed by the increase of return on entity (ROE), the increase of return on investment (ROI) and the increase of return on asset (ROA). The second-order construct Business development support is viewed as the extraversive factor used to evaluate the value of integrated AIS in terms of helping enterprises achieve the effectiveness.

- FaNEW2: Organizational process improvement, in the context of integrated AIS at organizational level, this IS helps enterprises with better internal performance through working process improvement (FaBUS4), cost saving (FaFIN2) in management and administration activities and working coorporation between departments (FaLEA2). These indicators show the enterprises' operational performance once integrated AIS-ERP is implemented. We find out the alignment of this research results with the result proved by Wikina (2008) about the impact of IT on organizational performance. In our conclusion, the second-order construct - Organizational process improvement, is viewed as the introversive factor used to evaluate the value of integrated AIS in terms of helping enterprises to achieve the effectiveness.

- FaNEW3: Market demand meet is the factor presenting the enterprises' ability to adapt to the market demand. According to the research of the market demand impact on the 
enterprises' adaptation from Smith et al. (2016), IT-applied factor is considered as a condition to help the enterprise adapt with the competitive market demand. In this article, we explore a new factor defining the effectiveness of integrated AIS is the Market demand meet. Once the integrated AIS helps enterprises achieve the effectiveness through the ability to adapt to customer demand including customer care (FaCUS2), production adjustment to new products production efficiency (FaBUS1) and product improvement (FaBUS3).

In general, the research result shows that although the strong existence of extraversive factor (business development support) and introversive factor (organizational process improvement), it is not sufficient to define the effectiveness of integrated AIS if we do not mention about the factor market demand meet.

\section{Conclusions and future research}

If we cannot evaluate the impact of IS on organizations we cannot identify the value that IS contributes to organizations. There are many previous researches showing the results of dependence of discrete and financial-factors which are unable to clearly pinpoint the effectiveness of IS (Joshi and Pant, 2008). Kohli and Grover (2008) belived that evaluating the IS in terms of effectiveness is one of manners to prove the business value of IS.

Refering to the previous research gaps, this research result provides the evidence for the business IS value in the form of factors defining the effectiveness of integrated AIS in ERP environment at organizational level. At the end, we have the answers to the research questions:

- To explore which factors defining the effectiveness of integrated AIS in ERP environment? We explore 3 second-order constructs that define the third-order construct - the effectiveness of integrated AIS. They are (1) business development support, (2) organizational process improvement and (3) market demand meet. In detail, The business development support construct is defined by 3 first-order factors including business competitiveness, customer management and financial profit. The organizational process improvement construct is defined by 4 firstorder factors including working process improvement, cost saving, working coorporation and internal management efficiency. The market demand meet construct is defined by 3 first-order factors including customer care, production efficiency and product improvement.

- To test research model of factors defining the effectiveness of integrated AIS in ERP environment at enterprises operating in Vietnam? The contribution of this research is starting from the BSC-based theoretical model, we collect data from the sample of Vietnamese integrated AIS-ERP enterprises, then we explore factors that define the effectiveness of integrated AIS in ERP environment. The results help enterprises' managers in terms of providing a model to evaluate the value of IS - specifically integrated AIS for business. This fact would convince the Hồ Chí Minh United Business Association to propagandize Vietnamese enterprises to implement an integrated AIS in ERP environment so as to improve the ITapplied effectiveness.

Our result also supplies several ideas to academic resaerches. Firstly, the adjusted model with 3 new explored factors including business development support, organizational process improvement and market demand meet which define the effectiveness of integrated AIS in ERP environment. This proves that the business value of IS is also suitable to the current IS research trend proposed by Bhimani and WillCocks (2014). We need to consider non-financial criteria and evaluate the IS value through the pervasiveness of business knowledge across departments in IT platform (Learn and Growth dimension of BSC theory). Secondly, 
Grabski et al. (2011) proposed 3 main AIS in ERP research trends including (1) research on success factors to AIS, (2) research on the impact of AIS on the whole organization and (3) the economic impact on AIS in ERP environment. The results of our research contribute knowledge to second research stream suggested by Grabski et al. (2011). Finally, the recent AIS researches from Vietnam still remain formulating, organizing and proposing the AIS to business entities (Đào Văn Thành, 2002; Trần Phước, 2007; Nguyễn Đăng Huy, 2011; Nguyễn Hữu Đồng, $2012 \ldots$..). Our research provides an evidence of evaluating effectiveness of integrated AIS in ERP environment based on enterprise management's viewpoints.

This research examines a multidimensional high-order construct which explains the effectiveness of integrated AIS at organizational level. It is suggested that further researches to re-examine the effectiveness of integrated AIS at different levels such as business departments, a specific business process or at individual level. In addition, building the IS evaluation model needs to change the IS type. Instead of AIS context, we suggest more researches on constructing the IS evaluation model with other IS such as E-commerce system, knowledge management system or even business intelligence system. The survey covers a representative sample mixed with different types of Vietnamese enterprises, future researches can be conducted into a specific industry in different countries. We should try to look at things from different interviees' viewpoints for future reference. Besides enterprise management, AIS researchers or integrated AIS-ERP solution suppliers,... could give us interesting and useful ideas

\section{References}

Bassellier, G., Benbasat, I., \& Reich, B. (2003). The influence of business managers' IT competence on championing IT. Information Systems Research Journal, 14(4), 317-336.

Bhimani, A., WillCocks, L. (2014). Digitisation, 'Big Data' and the transformation of accounting information. Accounting and Business Research Journal, 44(4), 469 - 490.

Blackburn, R., Logan, C., Renwick S. J. D., Donnelly, J. P. (2005). Higher-order dimensions of personality disorder: Hierarchical structure and relationships with the five-factor model, the interpersonal circle, and psychopathy. Journal of Personality Disorders, 19(6), 597-623.

Carr, N. G. (2003). IT doesn’t matter. Harvard Business Review Journal, 81(5), 41-49.

Chan, Y. (2000). IT value: The great divide between qualitative and quantitative and individual and organisational measures. Journal of Management Information Systems, 16(4), 225-261.

Chand, D., Hachey, G., Hunton, J., Owhoso, V., Vasudevan, S. (2005). A balanced scorecard based framework for assessing the strategic impacts of ERP systems. Journal of Computers in Industry, 56(6), 558-572.

Chapman, C. S., Kihn, L. A. (2009). Information system integration, enabling control and performance. Journal of Accounting, Organizations and Society, 34(2), 151-169.

Churchill, G. A. (1979). A paradigm for developing better measures of marketing constructs. Journal of Marketing Research, 16(1), 64-73.

Cronk, M. C., Fitzgerald, E. P. (1999). Understanding IS business value: Derivation of dimensions. Logistics Information Management Journal, 12(1), 40-49.

Thanh, D.V. (2002). Organizing public accounting system under computerized condition. Ph.D thesis. Vietnamese Financial Institution.

Daoud, H., Triki, M. (2013). Accounting Information Systems in an ERP Environment and Tunisian Firm Performance. The International Journal of Digital Accounting Research, 13(1), 1 - 35. 
Dasgupta, S., Sarkis, J., \& Talluri, S. (1999). Influence of information technology investment on firm productivity: A cross-sectional study. Logistics Information Management Journal, 12(1), 120-129.

Delone, W., McLean, E. (1992). Information systems success: The quest for the dependent variable. Journal of Information Systems Research, 3(1), 60-95.

Doll W.J., Torkzadeh G. (1988). Developing a multidimensional measure of system-use in an organizational context. Information and Management Journal 33(4), 171-185.

Dunn, S. C., Seaker R. F., \& Waller, M. A. (1994). Latent variables in business logistics research: Scale development and validation. Journal of Business Logistics, 15(2), 145-172.

Edwards, J. R. (2001). Multidimensional constructs in organisational behavior research: an integrative analytical framework. Journal of Organisational Research Methods, 4(2), 144-192.

El Louadi, M. (1998). The relationship among organisation structure, information technology and information processing in small Canadian firms. Canadian Journal of Administrative Science, 15(2), 99-180.

Evans, V. P. (1999). Higher-order factor analysis: An introductory primer. The Southwest Educational Research Association, San Antonio, Texas, January, 1999.

Farbey, B., Land, F., \& Targett, D. (1992). Evaluating investments in IT. Journal of Information Technology, 7(2), 109-122.

Gartner group (2016). ERP definition. Retrieved from http://www.gartner.com/technology/research/it-glossary.

Georgopoulos, B., Tannenbaum, A. (1957). A study of organisational effectiveness. American Sociological Review, 22(5), 534-540.

Grabski, S., Leech, S., \& Schmidt, P. (2011). A Review of ERP Research: A Future Agenda for Accounting Information Systems. Journal of Information Systems, 25(1), 37 - 78.

Grande, E. U.; Estebanez, R. P.; and Colomina, C. M. (2011). The impact of Accounting Information Systems (AIS) on performance measures: empirical evidence in Spanish SMEs. The International Journal of Digital Accounting Research, 11(1), $25-43$.

Grover, V., Jeong, S. R., \& Segars, A. H. (1996). Information systems effectiveness: The construct space and patterns of application. Information and Management Journal, 31(4), 177-191.

Hair, J. F., Black, B., Babin, B., Anderson, R. E., Tatham, R. L. (2005). Multivariate data analysis (6th ed.). Upper Saddle River, NJ: Pearson Education.

Huang, S. M., Ou, C. S., Chen, C. M., Lin, B. (2006). An empirical study of relationship between IT investment and firm performance: A resource-based perspective. European Journal of Operational Research, 173(3), 984-999.

Joshi, K., Pant, S. (2008). Development of a framework to assess and guide IT investments: an analysis based on a discretionary-mandatory classification. International Journal of Information Management, 28(3): 181-193.

Kaplan, R., Norton, D. (1992). The balanced scorecard - measures that drive performance. Harvard Business Review, 70(1): 71-79.

Kennerley, M., Neely, A. (2001). Enterprise resource planning: Analysing the impact. Integrated Manufacturing Systems Journal, 12(2): 103-113.

Kohli, R., Grover, V. (2008). Business value of IT: An essay on expanding research directions to keep up with the times. Journal of the Association for Information Systems, 9(1), 23-39.

Lee, J.; Kao, H. A., Yang S. (2014). Service Innovation and Smart Analytics for Industry 4.0 and Big Data Environment. The 6th CIRP Conference on Industrial Product-Service Systems 2014, 3-8.

Lina, K.; Edita, G. (2014). Development of Accounting System according to an Information Technology. Review of Economic Studies and Research, 7(2), 59-74.

Luftman, J., Brier. T. (1999). Achieving and sustaining business-IT alignment. California Management Review, 42(1), 109-122. 
Mackenzie, S. B., Podsakoff, P. M., \& Jarvis, C. B. (2005). The problem of measurement model misspecification in behavioral and organizational research and some recommended solutions. Journal of Applied Psychology, 90(4), 710-730.

Melville, N., Kraemer, K., \& Gurbaxani, V. (2004). Review: Information technology and organisational performance: An integrative model of IT business value. MIS Quarterly, 28(2), 283-322.

Milis, K., Mercken, R. (2004). The use of the balanced scorecard for the evaluation of information and communication technology projects. International Journal of Project Management, 22(2), 87-97.

Lien, N. B. (2013). Identifying and controlling the accounting information quality in ERP-applied environment in Vietnamese enterprises. Ph.D thesis. University of Economics Ho Chi Minh City.

Huy, N. D. (2011). Organizing accounting information systems under IT-applied conditions in Vietnamese importexport enterprises. Ph.D thesis. National Economics University.

Tho, N. D. (2013). Research methodology in business textbook $2^{\text {nd }}$ ed. HCM city: Finance publisher.

Dong, N. H. (2012). Improving accounting information systems for Vietnamese public univeristies. Ph.D thesis. National Economics University.

Rom, A., Rohde, C. (2007). Management accounting and integrated information systems: A literature review. International Journal of Accounting Information Systems, 8(1), 40-68.

Romney, M. B, Steinbart, P. J. (2012). Chapter 1: Accounting Information Systems: An Overview (12 ${ }^{\text {th }}$ ed., 30-31): Pearson Publisher.

Salehi, M.; Rostami V., Mogadam A. (2010). Usefulness of Accounting Information System in Emerging Economy: Empirical Evidence of Iran. International Journal of Economics and Finance 2(2).

Scapens, R. W., Jazayeri, M. (2003). ERP systems and management accounting change: Opportunities or impacts? A research note. European Accounting Review, 12(1), 201-233.

Schniederjans, M. J., Hamaker, J. L. (2003). A new strategic information technology investment model. Management Decision Journal, 41(1), 8-17.

Seddon, P., Staples, S., Patnayakuni, R., \& Bowtell, M. (1999). Dimensions of information systems success. Communications of the AIS, 2(20), 1-39.

Seddon, P.B. (1997). A Respecification and Extension of the DeLone and McLean Model of Information Systems Success, Information Systems Research, 8 (3), 240-253.

Sedera, D., Gable, G., Rosemann, M. (2001). A balanced scorecard approach to enterprise systems performance measurement. 12 $2^{\text {th }}$ Australasian Conference on Information Systems, Coffs Harbour Australia, December, 2001.

Shang, S., Seddon, P. B. (2002). Assessing and managing the benefits of enterprise systems: The business manager's perspective. Information Systems Journal, 12(4), 271-299.

Taipaleenmäki, J., Ikäheimo, S. (2013). On the convergence of management accounting and financial accounting the role of information technology in accounting change. International Journal of Accounting Information Systems, 14 (1), $321-348$.

Thong, J. Y. L., Yap, C. S. (1996). Information systems effectiveness: A user satisfaction approach. Journal of Information Processing and Management, 32(5), 601-610.

Phuoc, T. (2007). Solutions for improving the quality of accounting software usage in Vietnamese enterprises. Ph.D thesis. University of Economics Ho Chi Minh City.

Thanh, T. T. C., Minh Đ. N. (2015). ERP and its impact on financial accounting information quality. University of Economics Ho Chi Minh City seminar, $212-221$.

Walton, E. J., Dawson, S. (2001). Managers' perceptions of criteria of organizational effectiveness. Journal of Management Studies, 38(2), 173-199.

Wikina, S., B. (2008). Effective performance improvement and management strategies for the information technology industry. Performance Improvement Journal, 47(9), 19 - 25. 